\title{
Body-relatedness in somatoform disorder
}

Hanneke Kalisvaart, Saskia van Broeckhuysen, Martina Bühring, Marianne B. Kool, Sandra van Dulmen, Rinie Geenen

\section{Source}

Hanneke Kalisvaart, Saskia van Broeckhuysen, Martina Bühring, Marianne B. Kool, Sandra van Dulmen, Rinie Geenen. (2012). Definition and Structure of Body-RelatednesS from the Perspective of Patients with Severe Somatoform Disorder and Their Therapists. PLOS ONE, vol. 7 (8), e42534.

According to patients with somatoform disorders and their therapists, body-relatedness includes awareness of the body and self by understanding, accepting and adjusting to bodily signals, by respecting and regulating the body, by confiding and esteeming oneself and by being autonomous. 